\title{
ERRATUM
}

doi:10.1038/nature09047

\section{The genetics of ageing}

Cynthia J. Kenyon

Nature 464, 504-512 (2010)

In this review, the first line of the Figure 2 legend inadvertently states that the arrows depict changes in gene expression. The correct statement is that the arrows depict changes in gene-product activity. In the section entitled 'Inhibition of respiration', the second sentence inadvertently states that perhaps increasing respiration extends lifespan for one reason and inhibits it for another. The correct statement is that perhaps increasing respiration extends lifespan for one reason, and inhibiting respiration extends lifespan for another. In Figure 5, the pathways involving the intestinal cell were incorrectly illustrated. The correct figure is shown below.

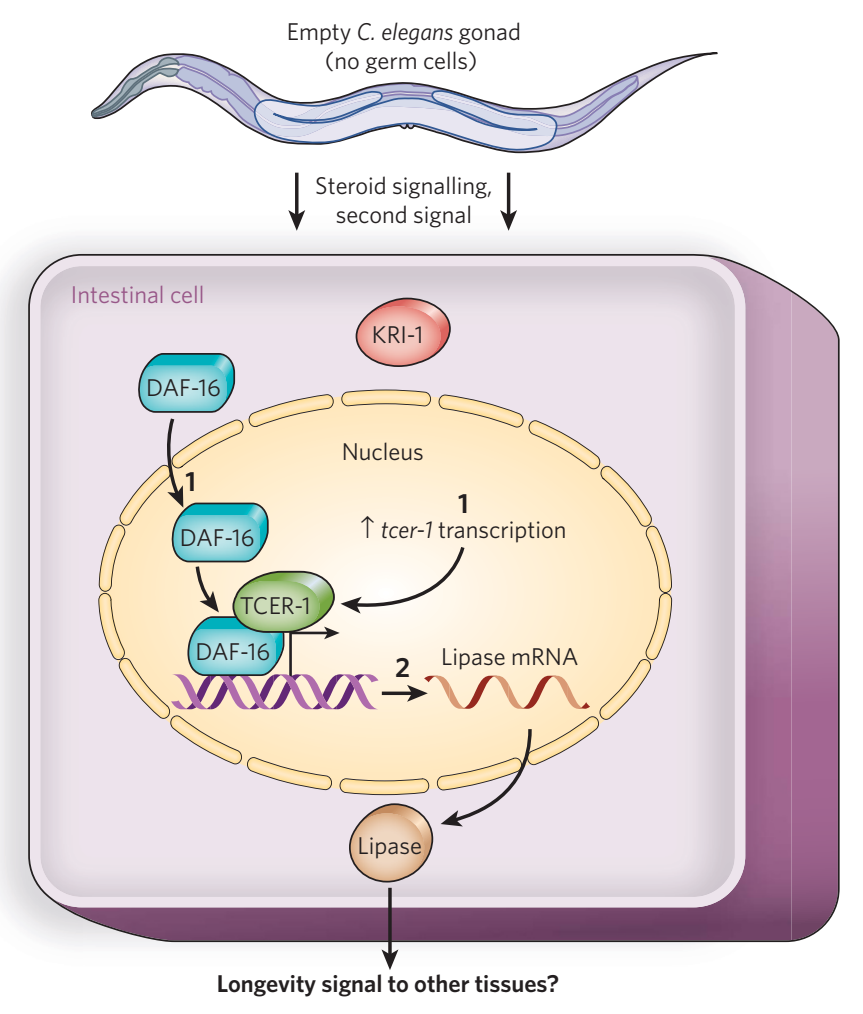

